\title{
Murdered women's children: A social emergency and gloomy reality
}

\author{
PIETRO FERRARA ${ }^{1,2}$, FRANCESCA IANNIELLO ${ }^{1}$, LORENZO SEMERARO ${ }^{2}$, GIULIA FRANC- \\ ESCHINI ${ }^{2}$, LUCIA LO SCALZO ${ }^{2}$, IDA GIARDINO ${ }^{3}$, GIOVANNI CORSELLO ${ }^{4}$ \\ ${ }^{1}$ Institute of Pediatrics, Catholic University Medical School, Rome, Italy \\ ${ }^{2}$ Service of Pediatrics, Campus Bio-Medico University, Rome, Italy \\ ${ }^{3}$ Department of Clinical and Experimental Medicine, University of Foggia, Foggia, Italy \\ ${ }^{4}$ Institute of Pediatrics, University of Palermo, Palermo, Italy
}

Corresponding author:

Pietro Ferrara

Institute of Pediatrics

Catholic University Medical School

L.go Francesco Vito, 1

00168, Rome, italy

E-mail: pietro.ferrara@unicatt.it p.ferrara@unicampus.it

ORCID 0000-0001-9449-3464

\section{ABSTRACT}

Femicide, defined as the killing of females by males because they are females, is becoming recognized worldwide as an important ongoing manifestation of gender inequality. Actual or imminent separation, abuser's access to firearms, prior threats with a weapon, prior threats to kill the victim, a stepchild in the household, problematic alcohol and illicit drug use, as well as mental health problems, are associated with a substantially higher risk of femicide. Little is known about the number of orphaned children who have instantaneously lost both parents. Sparse attention has been focused on children whose mother was murdered: these are difficult cases for child psychiatry teams. Decisions about protection could be made by judges, the police, social workers or officers that attend victims, on the basis of empirical data and not merely by using intuitive criteria. Key words: child, emergency, femicide

\section{INTRODUCTION}

Homicide is an important cause of premature mortality worldwide. (1) In Italy, from 2011 to 2016, after peaking in 2011-2012 with 555 murders, the number of murder cases dropped to 398 in 2015-2016. (2) The global homicide rate is almost four times higher for male (homicides) than for female homicides. (1) Femicide, defined as the killing of females by males because they are females, is becoming recognized worldwide as an important ongoing manifestation of gender inequality. Despite its high prevalence or widespread prevalence, only a few countries have specific registries dedicated to this issue. (3) According to homicide statistics, the murder of women is less common in Europe than in Asia, Africa and the Americas. Moreover, the prevalence of femicide in Italy, in particular of Intimate Partner Femicide (IPF), is one of the lowest in Europe: 0.9 homicides per 100.000 people. (4) The majority of women are killed by intimate partners (husbands, lovers, ex-husband or ex-lovers). Physical violence against the victim is the primary risk factor for IPF. (5)

Actual or imminent separation, abuser's access to firearms, prior threats with a weapon, prior threats to kill the victim, a stepchild in the household, problematic alcohol and illicit drug use, as well as mental health problems are also associated with a substantially higher risk of femicide. (5-8) The only sociodemographic risk factor for intimate partner femicide is the abuser's lack of employment. (5) Intimate partner homicide often involves the murder of family members or bystanders, such as the couple's children, relatives or new partners of the victims and have long-term consequences for remaining family members. (1)

Little is known about the number of orphaned children who have instantaneously lost both parents (one from death, the other from incarceration or suicide): in the last 15 years the number is up to 1628 orphaned children. Bureaucracy defines them as "secondary victims". (4)

The aim of this study was to assess the prevalence of femicides in Italy over the last years and to compare that with a pre- vious study. Although over the last several years there has been growing interest in the problem of femicide, to date there are no studies in the literature that focus specifically on children of murdered women. Even when publications concerning femicide include some information on children, the data are always limited to the description of a few isolated cases. (9) We focused on this important, usually ignored, aspect and we updated a previous study about the number of femicides occurring in Italy between 1st January, 2012 and 31st October, 2014.

Potential long lasting effects of these traumatic events for the children of a woman who dies a violent death are also discussed.

\section{METHODS}

The data used in this study come from an internet search for the number of femicides occurring in Italy between 1st January, 2015 and 31st October 2016. All violent female deaths that occurred in Italy were searched for using news websites, newspaper indexes, and internet search engines such as Google.

The search keywords included: homicide, femicide, intimate partner, children, family, femicide database and parental killing. We distinguished the victim's age, Italian macro area, victim's region of origin and relationship with the perpetrator (family member, current intimate partner, son, ex intimate partner etc.). Homicide characteristics studied included type of weapon causing the fatal injury (sharp object, firearm, strangulation /asphyxiation etc.). 
We also investigated the presence and the number of children in the household or family, their relationship with the perpetrator (father, step-father, other) and whether they witnessed the murder, were killed with their mother or were orphaned by this act.

\section{RESULTS}

In Italy, from 1st January, 2015 to 31st October, 2016 the total number of femicides was 233; a woman was murdered every three days in Italy. The age distribution into bands is shown in Table 1 .

Considering territorial distribution in Italy, we found that the majority of femicides occurred in Northern Italy: 62/116 (53,4 $\%)$ in 2016 and 54/117 in $2015(46,15 \%)$, in Central Italy in 23/116 (19,8\%) in 2016 and in $16 / 117(13,68 \%)$ in 2015 , in South Italy $31 / 116$ cases $(26,3 \%)$ in 2016 and $47 / 2017(40,17 \%)$ in 2015 (table 2). The victims' region of origin is shown in Table 3.

Cold arms, in the form of a sharp object (mostly knives), were the cause of death in $38 / 116$ cases $(32,5 \%)$ in 2016 and in $41 / 116$ cases $(35,04 \%)$ in 2015 ; firearms $35 / 116$ $(30,1 \%)$ in 2016 and $32 / 116(27,35 \%)$ in 2015; strangulation/asphyxiation $16 / 116$ $(13,7 \%)$ in 2016 and 20/117 (17,09 \%) in 2015 (Table 4).

Femicides were committed by a family member in 88/116 cases $(75,9 \%)$ in 2016 and in $101 / 117$ cases (86,3 \%) in 2015; friend /colleague/ neighbor in 5/116 cases $(4,3 \%)$ in 2016 and in $10 / 117$ cases $(8,5 \%)$ in 2015. Only in a few cases, did the woman not know the murderer: $18 / 116$ cases $(15,5 \%)$ in 2016 and $5 / 117$ cases $(4,3 \%)$ in 2015. We confirmed the passionate reason as the first reason for committing femicide: $24 / 116$ cases $(20,7 \%)$ in 2016 and in 44 cases $(37,6 \%)$ in 2015 (Table 5).

From 2001 to 2016, 1600 murdered women's children were found.

There were 1344 (84\%) minors (age < 18 years); a total of $640 / 1600(40 \%)$ were witnesses to the killing; 704/1600 (44\%) saw the mother's dead body. There were 320 cases of children whose father died by his own hand after killing their mother.

Information about where and with whom the minors were to live after their mother's murder was very scarce. Minors were placed with maternal grandparents in 944 cases and with community services in 400 cases. We also found that in 144 cases the children were placed with their aunts, uncles and paternal grandparents and with, brothers and sisters in 122 cases (Table 6).

Table 1. Victim's average age

\begin{tabular}{llllll}
\hline $\mathbf{2 0 1 6}$ & $\mathbf{n}$ & $\mathbf{\%}$ & $\mathbf{2 0 1 5}$ & $\mathbf{n}$ & $\mathbf{\%}$ \\
\hline$<25$ years & 12 & 10 & $<25$ years & 10 & 8,54 \\
\hline $25-34$ years & 16 & 13,8 & $25-34$ years & 17 & 14,53 \\
\hline $35-44$ years & 19 & 16,4 & $35-44$ years & 21 & 17,95 \\
\hline $45-55$ years & 18 & 15,5 & $46-60$ years & 37 & 31,62 \\
\hline $55-63$ years & 16 & 13,8 & $/$ & $/$ & $/$ \\
\hline / & & $61-75$ years & 12 & 10,26 \\
\hline over 64 years & 35 & 30,2 & $>75$ years & 18 & 15,38 \\
\hline
\end{tabular}

\section{Table 2. Victim's area of origin}

\begin{tabular}{llllll}
\hline 2016 & $\mathrm{n}$ & $\%$ & 2015 & $\mathrm{n}$ & $\%$ \\
\hline Central & 23 & 16 & Central & $19,8 \%$ & $13,68 \%$ \\
\hline North & 62 & 53,4 & North & 54 & 46,15 \\
\hline South & 31 & 26,3 & South & 47 & 40,17 \\
\hline
\end{tabular}

In another case, the maternal grandparents were elderly and too poor to take care of the child, so he was placed in a fosterhome. Finally, we evidenced 640 cases of children's relationship problems with their fosters and 624 cases of fosters who reported economic problems caused by a lack of financial contribution for the orphans. (10)

\section{DISCUSSION}

Very few studies are available about the incidence of femicides in Italy. According to EURES research performed in 2015 and 2016, a total of 233 femicides were recorded in Italy: 117 femicides committed in 2015 and 117 in 2016. $(11,12)$ Our findings for the years 2015-2016 show an increase in femicide compared to 20122014. (13,14) Although the Italian Government introduced an innovative "Law $\mathrm{n}^{\circ}$ 119-15.10.2013" (with rules to fight gender-based violence in order to prevent femicide), after an early downward trend, female victims increased again.

The Istanbul Convention came into force on 1 August 2014 to prevent and combat violence against women and domestic violence. As of December 2015, the convention was signed by 39 states, followed by ratification of the minimum eight Council of Europe states: Albania, Austria, Bosnia and Herzegovina, Italy, Montenegro, Portugal, Serbia, and Turkey. Later that year it was ratified by Andorra, Denmark, France, Malta, Monaco, Spain, and Sweden. In 2015 it was ratified also by Slovenia, Finland, Poland and the Netherlands, and in 2016 by San Marino, Belgium and Romania; and in 2017 by Georgia. (15) In Italy, positive long-term effects were not evident between 2015-2016. Further research to understand the underlying causes of this increasing trend in femicides is needed. Every year 66,000 women are violently killed globally. The rates of femicide differ depending on the specific country, but of the countries with the top 25 highest femicide rates, 50\% are in Latin America. (16) In Europe, in order to advance research clarity, improve the efficacy of policies for femicide prevention, and publish guidelines for the use of national policy-makers, A COST Action IS1206 has established the first pan-European coalition on femicide with researchers who are already studying the phenomenon nationally. (17) The term femicide has been used intensively in Italy and even exploited by the media, with the aim of raising awareness on the topic. Attention peaks on specific dates in the year (8th March, International Women's Day and 25th November, International day against violence against women), when most of the media will discuss the issue and conferences are organized. There is more attention from everyone: the media, law enforcement agencies, police force, institutions, citizens. This awareness-raising may discourage femicides. Our data show that further attention to prevention is needed.

Previous research performed by the same author, Ferrara and colleagues, revealed that the majority of femicides occurred in northern Italy and that the current and former intimate partners were the perpetrators in more than half of the homicide deaths of women in Italy. (13)

Prior findings revealed that actual or imminent separation appears to be a high- 
risk situation, since, in our data, the passionate motive is the most frequent motive behind femicide.

Our results are consistent with these findings: $72,6 \%$ of victims were $\leq 60$ years old in 2015. The rates were highest for women in the 46 to 60 age group, followed by women in the 35-44 age group.

We found that current and former intimate partners were the perpetrators in more than half of the homicide deaths of women in Italy.

The most popular method of killing was using a sharp object, mostly knives, followed by firearms and then by asphyxiation, according to previous findings.

Gun availability still increased homicide risk: this is probably due to gun-owning abusers' much greater likelihood of using a gun in the worst incident of abuse. $(18,19)$ From 2001 to 2016, 1600 murdered women's children were found: 1344/1600 (84\%) were minors (age $<18$ years). a total of $640 / 1600$ (40\%) were witnesses to the killing; 704/1600 (44\%) saw the mother's dead body. There were 320 cases of children whose father died by his own hand, after killing their mother.

We evidenced 640 cases of children's relationship problems with their fosters and 624 cases of fosters who reported economic problems caused by a lack of financial contribution for the orphans. Minors were placed with maternal grandparents in 944 cases and with community services in 400 cases. (10)

Overall, $90 \%$ of all femicides reported by us did not have information about placement, access and custody of children after the killing. Placement after the death is very problematic.

The caregivers often exert pressure on the child to forget what happened by not speaking about it, negating the child's version of events, and responding with silence and evasion to the child's questions so that children have difficulty in effectively mourning their losses. (20)

This suppression is particularly likely if carers are kin. (9) As attention is focused on the victim and on the perpetrator of the crime, the couple's children become the neglected victims.

Of all the traumatic events that children can experience, none can be more horrific than witnessing the murder of one parent by another.

Besides, children who witness parental homicides sometimes are left alone with the dead body of their mother, and may have to find help or attempt to defend her. Some of them were also witnesses to their father's subsequent suicide and may be the only source of information for the police and the social services.

Many studies have described regressive and maladaptive responses that accompany these traumatic events. These disorders include enuresis, encopresis, sleep disturbance, temper tantrums, flashbacks, dissociation, anxiety and psychosomatic disorders, and passive and aggressive behaviors. (21) According to research performed by Black and colleagues, most children present at the killing had symptoms of posttraumatic stress disorder, whereas they were not found in those who were absent from home at the time of the killing. (8) Moreover, several studies have concurred that violence observed by children has a high probability of being reenacted later in life. (22)

This is the second manuscript in Italy, written by the same author, Ferrara and colleagues, which seeks to raise awareness on this issue.

The children of mothers killed violently are usually entrusted to relatives or placed in foster homes and, in extreme cases, in foster families.

The removal of a child from its biological family causes devastating consequences, both psychological and physical. If treatment is neglected or postponed, adaptations to satisfactory and optimal functioning, both transitory and prolonged, can be severely compromised. Immediate and intensive care for these children and their family is essential. (23-29)

Black and colleagues, as a result of their experience with these troubled children, suggested some recommendations that include: immediately after the killing, children's placement should be with familiar people; primary health care services should be alerted about the children and early consultations sought from child mental health services; expert advice should be sought regarding the possibility of attending their mother's funeral and of visiting their father. (9)

In the longer term, permanent placement planning should begin as soon as possible: the emergency placement should not become permanent by default; therapeutic help should be available as needed, especially for children who witnessed the killing.

Improved ability to identify women who are at risk for IPF may facilitate prevention and enable more appropriate allocation of resources.

When women are identified as abused in medical settings, it is important to assess perpetrators' access to guns or another weapon and to warn women of the risk weapons present.

If a woman is planning to leave her abuser, it is critical to advise her not to confront him personally with her decision; instead, she needs to leave when he is not present and leave a note or call him later.

Different levels of prevention are possible and include strategies directed at risk factors for homicide in general; for example, many analyses suggest that increasing employment opportunities, preventing substance abuse, and restricting abusers' access to guns can potentially reduce rates of IPF.

\section{CONCLUSIONS}

Sparse attention has been focused on children whose mother was murdered: these are difficult cases for child psychiatry teams.

Decisions about protection could be made by judges, the police, social workers or officers that attend the victims, on the basis of empirical data and not merely by using intuitive criteria.

For this reason, long-term studies are needed to ascertain what happens to these children, to understand what are the most appropriate psychological treatments, the best decisions about contact with their father (when he is the murderer) and the best placement for these children. (30)

\section{REFERENCES}

1. Stöckl H, Devries K, Rotstein A, Abrahams N, Campbell J, Watts C, et al. The global prevalence of intimate partner homicide: a systematic review. Lancet 2013;382(9895):859-65.

2. The Statistics Portal [Online] 2016 [cited 2017 Jul 10]; Available from:URL: https://www.statista.com/statistics/614300/total-number-of-murders-italy/

3. Vives-Cases C, Goicolea I, Hernández A, Sanz-Barbero B, Gill AK, Baldry AC, et al. Expert Opinions on Improving Femicide Data 
Collection across Europe: A Concept Mapping Study. Plos-One 2016 Apr 14;11(4).

4. Lucio L. La strage delle donne: 116 femminicidi dall'inizio dell'anno. [Online]. 2016 [cited 2017 Jul 10]; Available from:URL: http:// www.repubblica.it/cronaca/2016/11/24/news/la_strage_delle_donne_116_femminicidi_dall_inizio_dell_anno_-152674911/.

5. Campbell JC, Webster D, Koziol-McLain J, Block C, Campbell D, Curry MA, et al. Risk factors for femicide in abusive relationships: results from a multisite case control study. Am J Public Health 2003;93(7):1089-97.

6. Koziol-McLain J, Webster D, McFarlane J, Block CR, Ulrich Y, Glass N, et al. Risk factors for femicide-suicide in abusive relationships: results from a multisite case control study. Violence Vict 2006;21(1):3-21.

7. Moracco KE, Runyan CW, Butts JD. Female intimate partner homicide: a population-based study. J Am Med Womens Assoc 2003;58(1):20-5.

8. Campbell JC, Glass N, Sharps PW, Laughon K, Bloom T. Intimate partner homicide: review and implications of research and policy. Trauma Violence Abuse 2007;8(3):246-69.

9. Black D, Harris-Hendriks J, Kaplan T. Father kills mother: post-traumatic stress disorder in the children. Psychother Psychosom 1992;57(4):152-7.

10. Associazione D.i.re (Donne in rete contro la violenza) and University of Naples. "Switch-off: orfani speciali dei femminicidi"from 2001 to 2016 [Online] 2016 [cited 2017 Jul 10]; Available from: URL: https://www.direcontrolaviolenza.it/wp-content/uploads/2017/04/ D.i.Re-C.V.-agg.-31_12_2016.pdf.

11.EURES Ricerche economiche e sociali". "Caratteristiche dinamiche e profili di rischio del femminicidio in Italia. Le tendenze 2015/2016” [Online] 2017 [cited 2017 Jul 10]; Available from: https://www.eures.it/

12.EURES, “Banca dati sugli omicidi dolosi in Italia nel 2015” [Online] 2016 [cited 2017 Jul 10]; Available from: https://www.eures.it/

13. Ferrara P, Caporale O, Cutrona C, Sbordone A, Amato M, Spina G, et al. Femicide and murdered women's children: which future for these children orphans of a living parent? Ital J Pediatr 2015 Sep 29;41:68.

14. Bonanni E, Maiese A, Gitto L, Falco P, Maiese A, Bolino G. Femicide in Italy: National scenario and presentation of four cases. Med Leg J 2014;82(1):32-7.

15. Council of Europe. Full list: Chart of signatures and ratifications of Treaty 210" [Online] 2014 [cited 2017 Jul 10]; Available from:URL: https://www.coe.int/en/web/conventions/full-list/-/conventions/treaty/210/signatures.

16. Weil S. Failed Femicides among Migrant Survivors, Qualitative Sociology Review 2016; 12(4):6-21.

17. Weil S. "Femicide across Europe" Femicide: Taking Action against Gender-Related Killing of Women and Girls 2015 [Online]; 4:118121.

18. Bailey JE, Kellermann AL, Somes GW, Banton JG, Rivara FP, Rushforth NP. Risk factors for violent death of women in the home. Arch Intern Med 1997;157(7):777-82.

19. Suffla S, Van Niekerk A, Arendse N. Female homicidal strangulation in urban South Africa. BMC Public Health $2008 ; 8: 363$.

20. Fantuzzo J, Lindquist C. The effects of observing conjugal violence on children: a review and analysis of research methodology. J Fam Violence 1989;4:77-94.

21. Egeland B, Jacobvitz D, Stroufe A. Breaking the cycle of abuse. Child Dev 1988;59(4):1080-8.

22. Burman S, Allen-Meares P. Neglected victims of murder: children's witness to parental homicide. Soc Work 1994;39(1):28-34.

23. Black D, Kaplan T. Father kills mother. Issues and problems encountered by a child psychiatric team. Br J Psychiatry 1988;153:624-30.

24. Ferrara P, Ianniello F, Cutrona C, Quintarelli F, Vena F, Del Volgo V, et al. A focus on recent cases of suicides among Italian children and adolescents and a review of literature. Ital J Pediatr 2014 Jul 15;40(1):69.

25. Ferrara P, Romani L, Bottaro G, Ianniello F, Fabrizio GC, Chiaretti A, et al. The physical and mental health of children in foster care. Iran J Public Health 2013 Apr;42(4):368-73.

26. Ferrara P, Vena F, Caporale O, Del Volgo V, Liberatore P, Chiaretti A, et al. Children left unattended in parked vehicles: a focus on recent italian cases and a review of literature. Ital J Pediatr 2013 Nov 6;39(1):71.

27. Garcovich S, Gatto A, Ferrara P, Garcovich A. Vulvar pyoderma gangrenosum in a child: a case report. Pediatr Dermatol 2009 SepOct;26(5):629-31.

28. Ferrara P, Corsello G, Sbordone A, Nigri L, Ehrich J, Pettoello-Mantovani M. Foster Care: A Fragile Reality Needing Social Attention, and Economic Investments. J Pediatr 2016;173:270-1.

29. Ferrara P, Corsello G, Basile MC, Nigri L, Campanozzi A, Ehrich J, et al. The economic burden of child maltreatment in high income countries. J Pediatr 2015;167(6):1457-9.

30. Corsello G, Ferrara P, Chiamenti G, Nigri L, Campanozzi A, Pettoello-Mantovani M. The child health care system in Italy. J Pediatr 2016 Oct;177S:S116-26. 